\title{
The effect of fluoride on bone
}

\section{By S. M. Weidmann, J. A. Weatherell and D. Jackson, Biological Research Unit,} Leeds University Dental School and Hospital, Leeds

Small quantities of fluoride appear to be beneficial to man, imparting an increased resistance to dental caries and producing no general ill effects. Even at minimal levels of ingestion fluoride accumulates in the hard tissues, but at relatively low intakes there is no observed pathological effect. At some point, however, depending upon the rate of ingestion, and possibly related to the concentration of fluoride in bones, skeletal lesions characteristic of chronic fluorosis develop. Few instances of human skeletal fluorosis have been reported, and most of our knowledge concerning this disease has been obtained from experimental animals and from farm animals grazing in fields contaminated with fluorides.

In view of the great interest in the use of fluoride in caries prevention, it is important to recognize the nature of the skeletal lesions, the level of ingested fluoride that can cause them, and the fluoride content of bone associated with the lesions. This paper briefly discusses these aspects of chronic skeletal fluorosis.

\section{Skeletal pathology of chronic fluorosis}

The most obvious effect of persistent high fluoride ingestion is a stimulation of osteoblastic activity resulting in the production of exostoses and the calcification of tendons, ligaments and, occasionally, muscles. Some bones are more prone to exostosis formation than others; the vertebras, ribs and pelvis, for instance, are more susceptible than the long bones. In an advanced state, however, the entire skeleton is involved. Pl. $\mathrm{x} a$ shows a lesion produced experimentally in the tibia of a sheep. Such localized deposition of new bone, frequently found at sites of muscle and tendon attachment (Bauer, 1945), would seem to suggest that a significant factor in the development of the lesion is the rich blood supply of these sites. Exostosis formation is not always so restricted; sometimes the entire surface of a bone may be invested with new tissue resulting in an overall increase in thickness (Pl. $\mathrm{I} b$ ). Blood supply is, therefore, not the sole factor governing the induction of fluorotic exostoses.

The extensive production of new bone in the fluorotic skeleton is usually accompanied by increased bone resorption. It has been suggested (Weinmann \& Sicher, 1955) that exostoses are formed in order to reinforce a weakened bone. This theory seems unlikely, since the areas of 'reinforcement' do not always coincide with the region weakened by resorption (Bauer, 1945). It appears, moreover, that resorption may be secondary to bone formation; in a series of chronically fluorosed rabbits exostoses were observed without signs of bone resorption, whereas resorption was never seen in the absence of new bone formation (Weatherell \& Weidmann, 1959). For rapid new bone formation the mineral requirement will be considerable and it is not unreasonable to assume that calcium salts are withdrawn from the skeleton to meet an increased demand.

The few descriptions of chronic skeletal fluorosis in man suggest that there is a greater tendency towards bone formation than towards destruction. The radiographic 
picture of human skeletal fluorosis, which has almost invariably constituted the means of diagnosis of the condition, is one of increased radio-opacity, to which the term osteosclerosis has frequently been applied. The limited number of determinations made of the density and degree of mineralization of exostoses suggest, however, that fluorotic bone is often less dense and less calcified than normal bone (Wolff \& Kerr, I938; Weatherell \& Weidmann, 1959). The apparent increase in density of the skeleton, as shown by X-rays, is most probably due to a greater thickness of bone and not to an increase in density, or degree of mineralization. Histologically, the exostoses often consist of coarse, primary woven bone in which secondary lamellar replacement is minimal. The low degree of mineralization, as indicated by the calcium : nitrogen ratio of the bone, is partly due to wide seams of uncalcified osteoid found in fluorotic bones of both man and animals (Roholm, 1937; Weatherell \& Weidmann, I959).

Skeletal fluorosis has been likened to a number of bone diseases. The dense radiographical picture of the skeleton has resulted in comparisons with osteosclerosis; the presence of broad osteoid seams has suggested osteomalacia; the way in which bone formation may proceed side by side with bone destruction is reminiscent of Paget's disease, and the often extensive resorption points to osteoporosis. Certainly, fluorotic bones can exhibit signs common to each of these conditions, but a unique distinction is the presence of high levels of fluoride in the bone.

\section{Dosage of fluoride and its concentration in bone associated with skeletal changes}

In view of the possibility of the introduction of water fluoridation, it is important to establish the level of fluoride ingestion at which changes are induced in the human skeleton, and also the fluoride concentration in bone associated with such changes. Table I presents results of investigations made upon groups of persons who had ingested various concentrations of fluoride in their drinking water. Radiographic examination failed to detect any skeletal changes in people consuming throughout life drinking water which contained 4 p.p.m. or less fluoride. At a level of 8 p.p.m., however, and also at 16 p.p.m. fluoride, about $10 \%$ of persons examined showed skeletal changes. At high levels of intake the prevalence of skeletal fluorosis was markedly increased. The critical dose at which skeletal damage might occur, as determined radiographically, would therefore seem to be in the region of 8 p.p.m. fluoride. From this evidence Hodge \& Smith (1954) have concluded that the safety factor of water fluoridation, at a level of I p.p.m. fluoride, is at least eightfold. This figure relates to American conditions, however, and the response to fluoride might be significantly influenced by diet.

Fluorotic lesions seem to be related to the amount of fluoride absorbed by the tissue. Although the fluoride bound in bone may not be a hazard per se (Hodge, 1952), the amount present does reflect previous levels of the ion in the surrounding tissue fluids. It is important, therefore, to establish the concentration of fluoride in human bone usually associated with the induction of skeletal changes.

Before an attempt is made to establish any such critical level of bone fluoride, allowance must be made for the fact that it is not uniformly distributed throughout 
Table I. Fluoride ingestion and fuorotic lesions in the human skeleton

Locality and reference

Oklahoma (Blue, I 938)

Kempton (Hodges, Fareed, Ruggy \& Chudnoff, r941)

Bureau (Hodges et al. I94I)

Lubbock (McCauley \& McClure, 1954)

Amarillo (McCauley \& McClure, 1954)

Texas and Oklahoma (Stevenson \& Watson, 1957)

Bartlett (Dean, 1944)

Pampas (Capizzano, Valotta \& Megy, I 940)

Southern India (Pandit, Raghavachari, Rao \&

Krishnamurti (I940)

Madras (Shortt, McRobert, Barnard \& Nayar, 1937)

\begin{tabular}{|c|c|c|c|}
\hline $\begin{array}{c}\text { Fluoride } \\
\text { ingestion } \\
\text { (mg F/day) }\end{array}$ & $\begin{array}{c}\text { Exposure } \\
\text { (years) }\end{array}$ & $\begin{array}{l}\text { No. of } \\
\text { persons } \\
\text { examined }\end{array}$ & $\begin{array}{c}\text { No. of } \\
\text { persons } \\
\text { with } \\
\text { lesions }\end{array}$ \\
\hline $\mathrm{I}-2$ & - & 25 & $\circ$ \\
\hline $1 \cdot 2-3$ & $0-6 r$ & 86 & 0 \\
\hline $2 \cdot 5$ & I 8-68 & $3 \mathrm{I}$ & 0 \\
\hline $3 \cdot 5-4 \cdot 5$ & $7-14$ & 690 & 0 \\
\hline $3 \cdot 3-6 \cdot 2$ & $7-14$ & 591 & $\circ$ \\
\hline $4-8$ & $44^{-8} 5$ & - & 23 \\
\hline 8 & - & II 4 & I 3 \\
\hline I6 & - & 178 & 21 \\
\hline $5^{-20}$ & - & I 192 & $3^{87}$ \\
\hline $20-50$ & $\ldots$ & - & 10 \\
\hline
\end{tabular}

the skeleton. The extent to which it is taken up depends upon the age of bone, the type of bone and the particular region of bone studied. Thus, young bones take up the element more readily than older bones (Zipkin \& McClure, I952), cancellous bone absorbs more fluoride than compact bone, and higher concentrations are found in the surface layers of bone than within the tissue. In general, the rate of fluoride uptake correlates with the biological activity of bone.

There are not many instances reported in the literature in which fluoride was determined in human bones with known fluorotic skeletal changes. One is that of a negro who was exposed for 18 years to finely ground rock phosphate dust containing $3.88 \%$ fluoride (Wolff \& Kerr, I 938 ). The cortical compacta of the long bones contained I $800-2900$ p.p.m. fluoride and a cross-section of rib 5600 p.p.m. fluoride (values in this paper being calculated to a basis of dry, fat-free bone). Two more subjects, in whom skeletal changes were observed radiographically, were shown by Roholm (I937) to have had bone fluoride levels of $3280-357^{\circ}$ and $693^{\circ-10} 700$ p.p.m.

Based on these findings, and on evidence obtained from animal studies, the concensus of opinion appears to be that as much as 5000-6000 p.p.m. fluoride in bone does not constitute a physiological hazard. Jackson \& Weidmann ( $195^{8}$ ) considered, for instance, that the critical threshold in compact bone might be somewhere between 2000 and 3000 p.p.m. and that the corresponding value for pure cancellous bone is $4000-6000$ p.p.m. fluoride. These estimates may be rather conservative, since higher levels have been tolerated without skeletal damage. Thus, ribs from three persons resident in West Hartlepool who had consumed drinking water with $\mathrm{I} \cdot 9$ p.p.m. fluoride for 52, 64 and 68 years contained over 6000 p.p.m. fluoride in cancellous bone. Similarly, rib bone from a woman of Bartlett (Texas) was shown to contain 6300 p.p.m. fluoride without concomitant lesions (McCann, 1960). The fluoride content of the drinking water in Bartlett was 8 p.p.m.

Despite these inconsistencies in man, numerous additional observations made in animals make it plausible to consider the concentration of fluoride in bone as a reliable index for a toxic threshold beyond which skeletal lesions might reasonably 
be expected (H. C. Hodge, I962, unpublished). In support of this view, Hodge quotes the case of a 22-year-old soldier, who had consumed water containing not more than 5.7 p.p.m. fluoride since the age of 7 years but who exhibited signs of skeletal fluorosis (Linsman \& McMurray, I943). His bones contained 5000-5500 p.p.m. fluoride, however. This patient suffered from renal insufficiency which had reduced his urinary excretion to such a degree that the rate of skeletal fluoride incorporation increased considerably.

The rate of fluoride uptake is obviously an important factor in the development of skeletal lesions. Skeletal fluoride levels might be similar in two individuals, but if in one of them the level was attained after a relatively short period, and in the other after the ingestion of small amounts of fluoride over a long period of time, lesions might develop in the first and not in the second.

\section{Water fluoridation and skeletal fuoride}

There are two crucial questions fundamental to the practical issue of fluoridation: (a) to what level does the concentration of fluoride rise in human bone when drinking water containing I p.p.m. fluoride is consumed throughout life, (b) is this level within the concentration considered to be a toxic threshold of fluoride in bone.

Several investigations have been made to determine the concentration to which fluoride in bone may rise after lifelong ingestion of small amounts of fluoride naturally occurring in the drinking water. Glock, Lowater \& Murray (194I) estimated the fluoride content of a number of ribs obtained from two London hospitals. Their samples, presumably, included both cortical and cancellous bone. All the ribs examined were without obvious signs of fluorosis, although two specimens contained over 2500 p.p.m. fluoride. Another survey was carried out by Smith, Gardner \& Hodge (I 953) in Rochester, USA, where the fluoride content of the drinking water was 0.06 p.p.m., and a third investigation was made upon material from Leeds (<0.5 p.p.m.), South Shields (I.2 p.p.m.) and West Hartlepool (I.9 p.p.m.) by Jackson \& Weidmann (1958). Rib bone was investigated in each survey and so the results are comparable. All these workers showed that the fluoride content of bone increased with age.

An interesting difference between the results for ribs from Rochester and Leeds was that, whereas in Rochester the fluoride content increased progressively throughout life, the level in Leeds ribs reached a plateau at about the age of 55 years. Similar plateaus were achieved at the same age in the specimens from South Shields and West Hartlepool but were established at a higher level owing to the greater amounts of fluoride in the water (Fig. I). Apparently, when the concentration in water is high enough, a steady state is established at which fluoride deposition balances its removal from the skeleton. At lower fluoride concentrations, such as that prevailing in Rochester, this condition does not appear to be achieved. The present fluoride content of the water in South Shields is 0.8 p.p.m. but it was for many years at a level of I.2 p.p.m., and hence the fluoride values of rib bone in this area are characteristic of those in a tea-drinking community whose water has been artificially fluoridated. At this level of fluoridation, the cancellous part of rib bone of a subject 


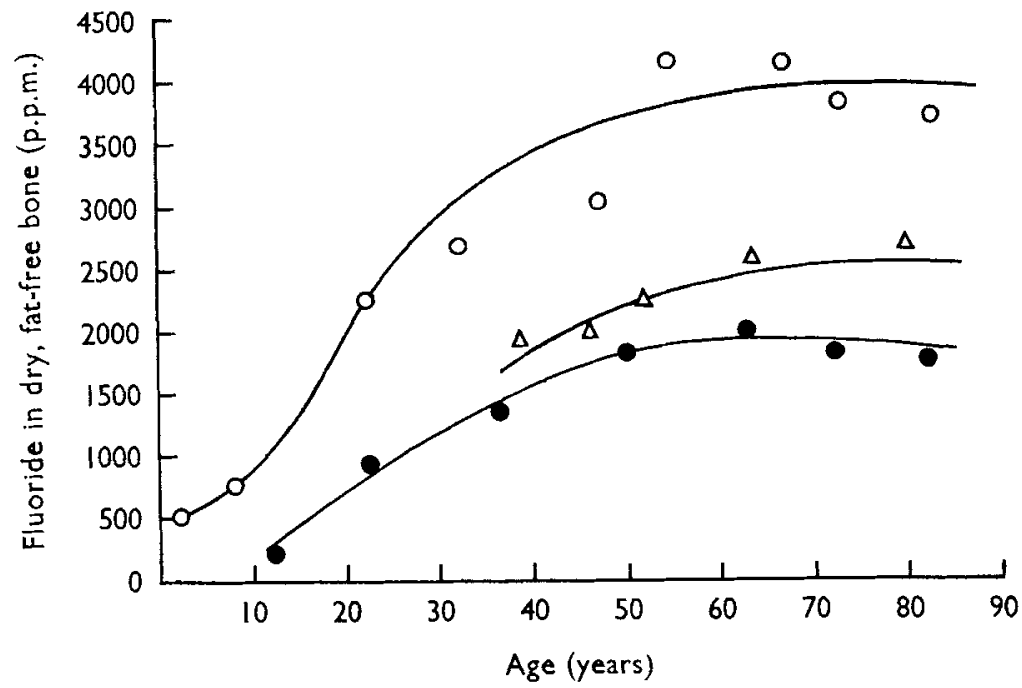

Fig. I. Variation in fluoride content of human rib cancellous bone with age, in persons from: West Hartlepool $(O)$, fluoride content of drinking water $1 \cdot 9$ p.p.m.; South Shields $(\triangle)$, fluoride content of drinking water 0.8 p.p.m.; Leeds ( $\bullet$ ), fluoride content of drinking water $<0.5$ p.p.m.

(Reproduced by permission from 7. Path. Bact. (1958), 76, 451.)

aged 55 years contained about 2500 p.p.m. fluoride (Fig. I). This is considerably below the danger level of fluoride present in cancellous bone suggested by Jackson \& Weidmann (1958). The fluoride content of rib bone from West Hartlepool (where the water contained I.9 p.p.m.) reached much higher levels than that of bones from Leeds or South Shields. At the age of 55 years, the cancellous fraction of these bones contained about 4000 p.p.m. fluoride. This concentration is approaching the proposed toxic threshold and it was, therefore, decided to examine ribs from lifelong residents of West Hartlepool for the earliest signs of skeletal fluorosis. Thirty specimens were obtained from persons who, as far as could be ascertained, had lived in West Hartlepool throughout life and had died suddenly. As a control to this study, twenty ribs were taken from Leeds (water content $<0.5$ p.p.m.). The fluoride content of each sample of bone was determined and an attempt made to compare not only ribs of a similar age from each community, but those specimens that had a representative fluoride content for each age range. In none of the West Hartlepool samples, some of which contained over 6000 p.p.m. fluoride, were there any gross signs of skeletal fluorosis.

A more detailed histological examination was, therefore, carried out and evidence sought from histological sections for early signs of the disease. Comparisons were made between the groups for increases in the width of rib cortex and thickening of the costal trabeculae, both effects having been pronounced in the study of Wolff $\&$ $\operatorname{Kerr}(1938)$ and in the descriptions of Roholm (1937). The relative numbers of costal trabeculae in each sample were measured to ascertain whether or not resorptive processes had been affected, and an assessment was also made of the extent of resorption areas within the compacta. In none of these histological aspects were any 
differences found between the rib specimens from West Hartlepool and those from Leeds. It was concluded, therefore, that a lifelong consumption of water containing a concentration of fluoride of about twice that proposed in artificial fluoridation would not result in any marked changes in bone.

\section{Conclusions}

Although it is well known that the ingestion of high levels of fluoride can give rise to severe lesions in the skeletal tissues, such effects have never been found radiographically in persons using a water supply containing less than 4 p.p.m. fluoride throughout life.

A histological study of thirty ribs taken from deceased residents of a region where the drinking water contained $\mathrm{I} \cdot 9$ p.p.m. fluoride revealed no changes characteristic of skeletal fluorosis.

Although even at a level of I p.p.m. fluoride in the drinking water, the concentration of the element in bone increases with age, the level reached after lifelong ingestion of water containing I p.p.m. fluoride would be appreciably lower than that associated with the condition of skeletal fluorosis.

\section{REFERENCES}

Bauer, W. H. (1945). Amer. F. Orthodont. 31, 700.

Blue, J. A. (1938). F. Okla. med. Ass. 31, 295.

Capizzano, N., Valotta, J. \& Megy, F. R. (1940). Rev. Med. Cienc, afin., B. Aires, 2, I9.

Dean, H. T. (1944). Quoted by Hodge \& Smith (1954).

Glock, G. E., Lowater, F. \& Murray, M. M. (I94 I). Biochem. F. 35, I235.

Hodge, H. C. (1952). Transactions of the Fourth Canference on Metabolic Interrelations. Vol. 4, p. 250. New York: Josiah Macy Jr. Foundation.

Hodge, H. C. \& Smith, F. A. (1954). In Fluoridation as a Public Health Measure, p. 79. [J. H. Shaw, editor.] Washington: American Association for the Advancement of Science.

Hodges, P. C., Fareed, O. J., Ruggy, G. \& Chudnoff, J. S. (1941). F. Amer. med. Ass. 117, 1938.

Jackson, D. \& Weidmann, S. M. (1958), F. Path. Bact. 76, 45 I.

Linsman, J. F. \& McMurray, C. A. (1943). Radiology, 40, 474.

McCann, H. G. (1960). Arch. industr. Hlth, 21, 336.

McCauley, H. B. \& McClure, F. J. (1954). Publ. Hlth Rep., Wash., 69, 67 I.

Pandit, C. G., Raghavachari, T. N. S., Rao, D. S \& Krishnamurti, V. (1940). Indian F. med. Res. 28, 533.

Roholm, K. (1937). Fluorine Intoxication. London: H. K. Lewis \& Co. Ltd.

Shortt, H. E., McRobert, G. R., Barnard, 'T. W. \& Nayar, A. S. M. (1937). Indian Y. med. Res. $25,553$.

Smith, F. A., Gardner, D. E. \& Hodge, H. C. (1953). Fed. Proc. r2, 368.

Stevenson, C. A. \& Watson, R. A. (I957). Amer. $\mathscr{F}$. Roentgenol. 78, 13.

Weatherell, J. A. \& Weidmann, S. M. (1959). Y. Path. Bact. 78, 233.

Weinmann, J. P. \& Sicher, H. (1955). Bone and Bones, and ed. London: Henry Kimpton.

Wolff, W. A. \& Kerr, E. G. (1938). Amer. F. med. Sci. 195, 493.

Zipkin, I. \& McClure, F. J. (1952). F. Nutr. 47, 6 I I.

\section{EXPLANATION OF PLATE}

a. Localized fluorotic exostosis produced experimentally in the tibia of a sheep.

$b$. General thickening in the tibia of a rabbit caused by fluorotic exostosis.

(Reproduced by permission from 7 . Bact. Path. (1959), 78, 233.) 


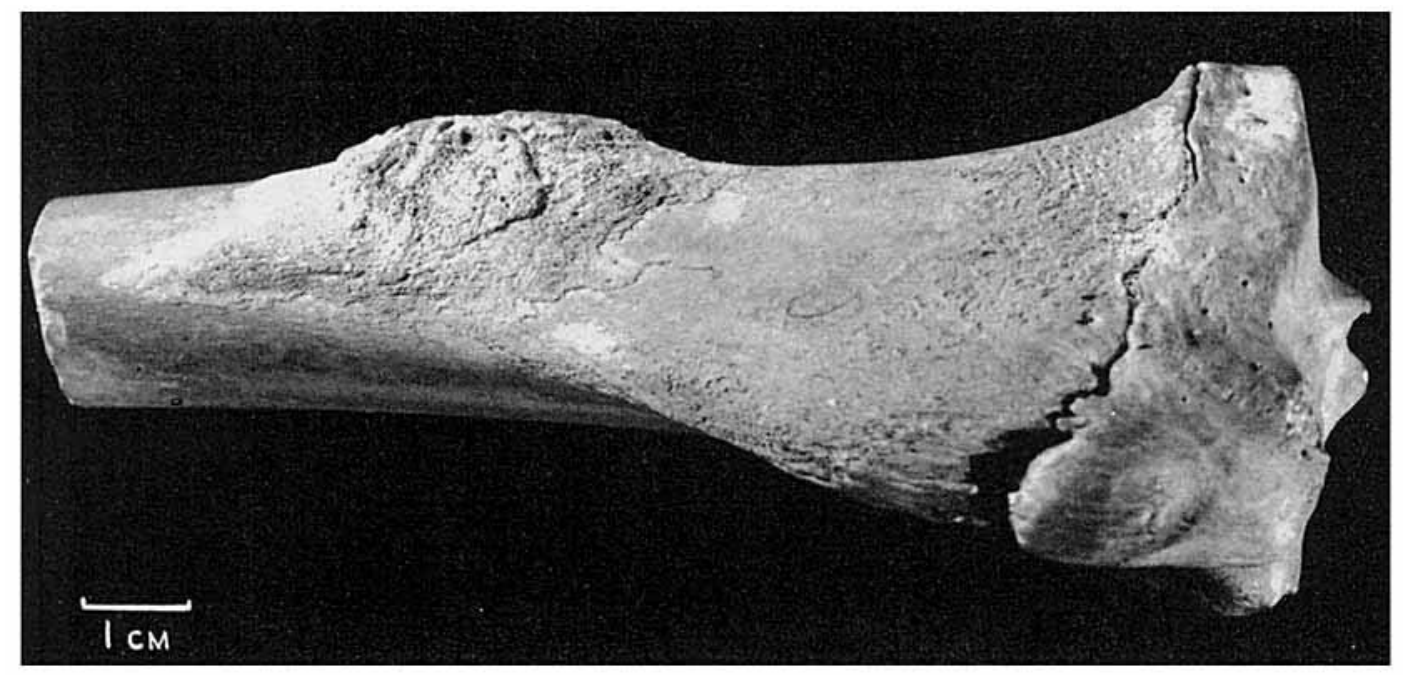

(a)

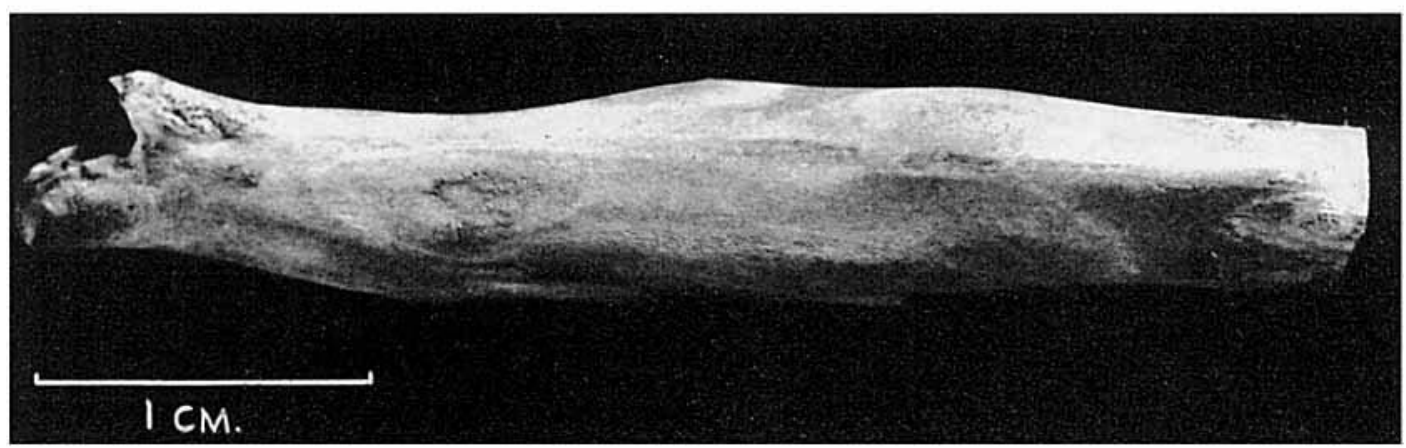

(b)

S. M. WEIDMANN, J. A. WEATHERELL \& D. JACKSON 